\title{
Е.Г. Крылова
}

Институт биологии внутренних вод им. И.Д. Папанина РАН, n. Борок, Ярославская обл., Россия

\section{Прорастание семян и развитие проростков прибрежно-водных растений под действием сульфата цинка}

\begin{abstract}
Изучено влияние сульфата цинка (1-500 мг/л) на прорастание семян и развитие проростков гелофита частуха подорожниковая (Alisma plantagoaquatica L.), гелогигрофита поручейник широколистный (Sium latifolium L.) и гигрофита ситник развесистый (Juncus effusus L.). Выявлено увеличение устойчивости видов к действию сульфата цинка в зависимости от степени обводненности (от меньшей - $к$ большей) их местообитаний: наиболее устойчив гелофит, средняя устойчивость отмечена у гелогигрофита, наименьшая - у гигрофита. Высокие концентрачии цинка (от 50 мг/л) вызывали отмирание корней проростков и некроз листьев у всех видов изученных растений.

Ключевые слова: сульфат иинка; прорастание семян; развитие проростков; Alisma plantago-aquatica; Sium latifolium; Juncus effusus.
\end{abstract}

\section{Введение}

Тяжелые металлы (ТM) относятся к числу распространенных и весьма токсичных загрязняющих веществ $[1,2]$. Поступление их в биосферу вследствие техногенного рассеивания осуществляется разнообразными путями. Цинк попадает в природные воды в результате процессов разрушения и растворения горных пород и минералов, а также со сточными водами рудообогатительных фабрик и гальванических цехов. В сельском хозяйстве источниками цинка являются ил и сточные воды, используемые в качестве удобрений. В воде он существует главным образом в ионной форме или в виде минеральных и органических комплексов. Иногда встречается в нерастворимых формах: гидроксидах, карбонатах, сульфидах и др. В речных водах концентрация цинка обычно колеблется от 3 до 120 мкг/дм³ [3].

Цинк относится к числу активных микроэлементов, влияющих на рост и нормальное развитие организмов, входит в состав активных центров многих ферментов и выполняет разнообразные физиологические функции [4]. В то же время многие соединения цинка токсичны, прежде всего его сульфат и хлорид. Высокие концентрации цинка замедляют рост и развитие растений, ингибируют накопление биомассы надземных и подземных органов, вызывают хлороз молодых листьев и нарушают фотосинтез, дыхание, транспира- 
цию, снижают усвоение меди и железа [5-7]. Цинк имеет значительную биохимическую активность и высокую комплексообразующую способность, при этом его подвижность умеренная. Это является причиной невысокой, по сравнению с другими ТМ, токсичности [8].

$\mathrm{B}$ настоящее время данных по влиянию ионов $\mathrm{Zn}^{2+}$ на начальные этапы онтогенеза (прорастание семян и развитие проростков) водных растений в зарубежной литературе не обнаружено, в отечественной литературе они единичны [12-13]. Сравнения по экологическим группам не проводилось.

Цель данного исследования - выявление влияния раствора сульфата цинка на прорастание семян и развитие проростков гелофита частуха подорожниковая (Alisma plantago-aquatica L.), гелогигрофита поручейник широколистный (Sium latifolium L.) и гигрофита ситник развесистый (Juncus effusus L.) - видов, широко распространенных на водоемах средней полосы России. Чувствительность начальных этапов онтогенеза этих видов к действию солей ТМ покажет возможность использования их в разработке вопросов индикации загрязнения водоемов.

\section{Материалы и методики исследования}

Семена собирали с растений в августе - сентябре 2008 г. в Ярославской области на увлажненных побережьях малых рек Ильдь и Латка. После холодной влажной стратификации в течение 4-5 месяцев по 25 шт. проращивали в люминостате в чашках Петри при температуре $20-25^{\circ} \mathrm{C}$ на фильтровальной бумаге, смоченной растворами соли $\mathrm{ZnSO}_{4} \times 7 \mathrm{H}_{2} \mathrm{O}$ в разных концентрациях $(1,10,25,50,100,250,500$ мг/л). Концентрации выбраны по рекомендации специалистов Ботанического института им. В.Л. Комарова $\mathrm{PAH}$, рассчитаны на ион цинка $\mathrm{Zn}^{2+}$ и приготовлены на дистиллированной воде. Высокие концентрации использовали для выявления предела токсичности цинка для прорастания семян (т.е. той концентрации, при превышении которой семена не прорастают). Повторность опытов трехкратная, освещенность 3200 лк, фотопериод 9/15 (свет/темнота). Длительность эксперимента 15 сут. Контроль - дистиллированная вода. Определяли лабораторную всхожесть (процент проросших семян от общего числа в конце эксперимента) и проводили наблюдения за развитием проростков. За нормальное развитие принимали состояние проростков, их листьев и корней, свойственное конкретным видам, без каких-либо повреждений и нарушений окраски. Данные обрабатывали с использованием программы Statsoft STATISTICA for Windows 6.0, построение графиков выполнено в программе Microsoft Office Excel 2003. Результаты экспериментов представлены в таблице в виде средних арифметических и их стандартных отклонений. 


\section{Результаты исследования и обсуждение}

Влияние сульфата цинка на прорастание семян. Семена всех видов прорастали дружно: частухи подорожниковой - на 2-е сутки, поручейника широколистного и ситника развесистого - на 3-4-е, что позволяет говорить об их нормальном дозревании и способности к прорастанию. Продолжительность прорастания составила 6 сут для первого вида и 10-12 сут - для второго и третьего. Увеличение концентрации $\mathrm{Zn}^{2+}$ не влияло на продолжительность периода прорастания. Лабораторная всхожесть была высокой у поручейника, средняя - у частухи и низкая - у ситника (таблица).

\section{Основные показатели прорастания семян и развития проростков при их проращивании на растворах сульфата цинка различных концентраций (среднее для трех повторностей) /}

Main parameters of seed sprouting and seedling development during their germination at various concentrations of zink sulphate solution (average for three replicates)

\begin{tabular}{|c|c|c|c|c|c|}
\hline \multirow[t]{2}{*}{\begin{tabular}{|c|} 
\\
Концентрация \\
$\mathrm{ZnSO}_{4} \times 7 \mathrm{H}_{2} \mathrm{O}$, \\
мг/л/ \\
Concentration \\
$\mathrm{ZnSO}_{4} \times 7 \mathrm{H}_{2} \mathrm{O}, \mathrm{mg} / 1$
\end{tabular}} & \multirow{2}{*}{\begin{tabular}{|c|} 
Появление \\
семядольных \\
листьев / \\
$\begin{array}{c}\text { Emergence } \\
\text { of cotyledon } \\
\text { leaves }\end{array}$ \\
cyт / days \\
\end{tabular}} & \multicolumn{2}{|c|}{$\begin{array}{l}\text { Длина, мм / } \\
\text { Length , mm }\end{array}$} & \multirow[t]{2}{*}{$\begin{array}{c}\text { Отмирание } \\
\text { листьев и } \\
\text { корней, сут / } \\
\text { Dieback of } \\
\text { leaves and } \\
\text { roots, days }\end{array}$} & \multirow[t]{2}{*}{$\begin{array}{c}\text { Лабораторная } \\
\text { всхожесть, \% } \\
\text { Laboratory } \\
\text { germination, } \\
\%\end{array}$} \\
\hline & & $\begin{array}{c}\text { листьев / } \\
\text { leaves }\end{array}$ & $\begin{array}{c}\text { корней / } \\
\text { roots }\end{array}$ & & \\
\hline \multicolumn{6}{|c|}{ Sium latifolium L. } \\
\hline Контроль / Control & 7 & $7-9$ & $6-8$ & - & $88,0 \pm 6,1$ \\
\hline 1 & 8 & $6-8$ & $5-7$ & - & $89,2 \pm 2,0$ \\
\hline 10 & 8 & $6-8$ & $5-7$ & - & $92,0 \pm 4,0$ \\
\hline 25 & 9 & $5-6$ & $3-4$ & - & $90,8 \pm 1,3$ \\
\hline 50 & 10 & $5-6$ & $3-4$ & 13 & $76,0 \pm 8,3$ \\
\hline 100 & 11 & $4-3$ & $1-2$ & 12 & $84,0 \pm 2,3$ \\
\hline 250 & - & 0 & $0-1$ & 7 & $53,2 \pm 4,8$ \\
\hline 500 & - & 0 & $0-1$ & 7 & $4,0 \pm 0$ \\
\hline \multicolumn{6}{|c|}{ Alisma plantago-aquatica L. } \\
\hline Контроль / Control & 4 & $10-12$ & $7-9$ & - & $49,3 \pm 22,0$ \\
\hline 1 & 4 & $10-12$ & $7-9$ & - & $50,7 \pm 8,3$ \\
\hline 10 & 4 & $8-10$ & $5-7$ & - & $77,3 \pm 4,6$ \\
\hline 25 & 4 & $6-8$ & $4-6$ & - & $57,3 \pm 12,2$ \\
\hline 50 & 4 & $5-6$ & $2-4$ & 8 & $45,3 \pm 11,5$ \\
\hline 100 & 4 & $4-5$ & $0-1$ & 8 & $56,0 \pm 14,4$ \\
\hline 250 & 5 & $2-4$ & 0 & 5 & $64,0 \pm 16,0$ \\
\hline 500 & - & 0 & 0 & 5 & $54,7 \pm 4,6$ \\
\hline \multicolumn{6}{|c|}{ Juncus effusus L. } \\
\hline Контроль / Control & 5 & $5-7$ & $2-4$ & - & $27,4 \pm 3,9$ \\
\hline 1 & 5 & $4-6$ & $2-4$ & - & $41,6 \pm 17,5$ \\
\hline 10 & 5 & $4-6$ & $1-2$ & 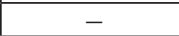 & $26,0 \pm 5,3$ \\
\hline 25 & 6 & $2-4$ & $1-2$ & 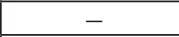 & $36,8 \pm 12,9$ \\
\hline 50 & 7 & $0-2$ & 0 & 10 & $4,1 \pm 1,2$ \\
\hline 100 & - & 0 & 0 & 4 & $2,1 \pm 0,9$ \\
\hline 250 & - & 0 & 0 & 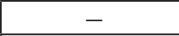 & 0 \\
\hline 500 & 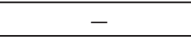 & 0 & 0 & 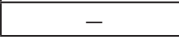 & 0 \\
\hline
\end{tabular}



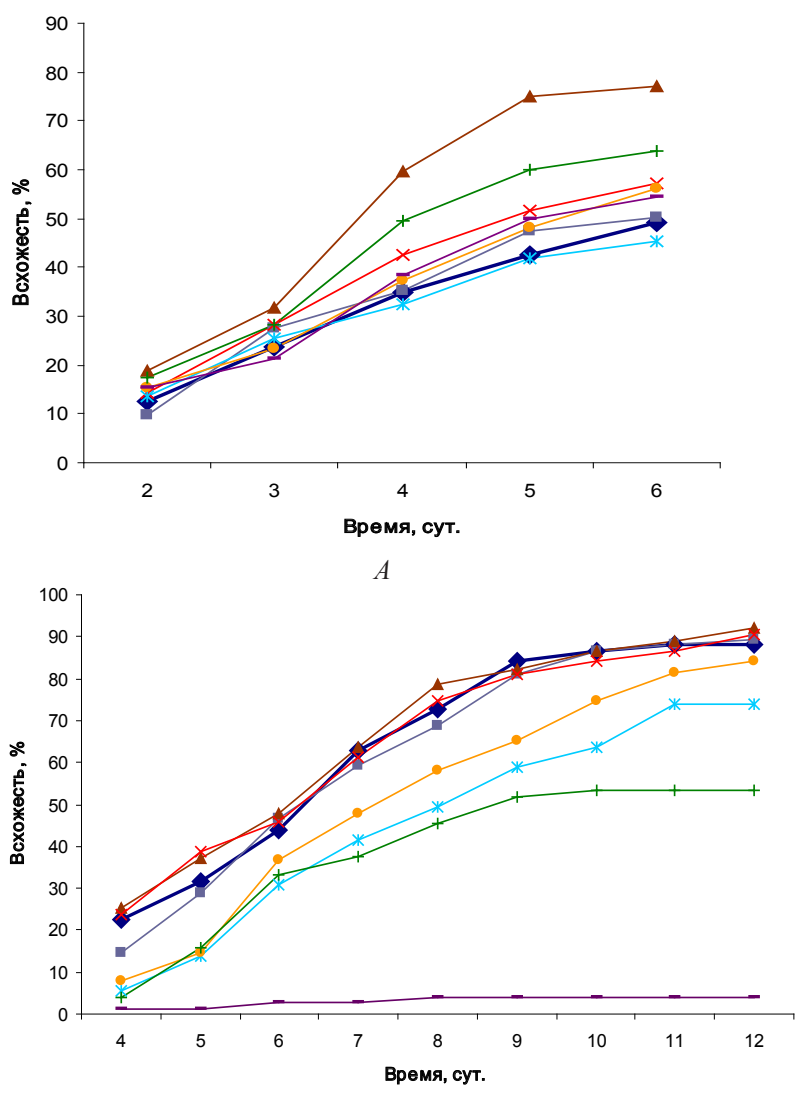

$B$

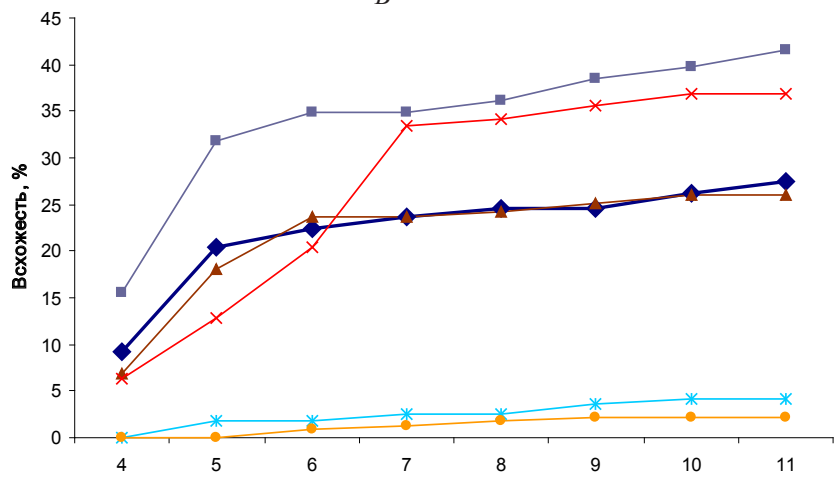

Время, сут.

\begin{tabular}{|c|c|c|c|}
\hline $\begin{array}{l}\longrightarrow \text { Контроль } \\
\approx \\
* 50 \mathrm{Mr} / л\end{array}$ & $\begin{array}{l}\longrightarrow-1 \mathrm{mr} / \Omega \\
\longrightarrow-100 \mathrm{mr} / \Omega\end{array}$ & $\begin{array}{l}\longrightarrow-10 \mathrm{mr} / \Omega \\
\longleftarrow 250 \mathrm{mr} / \Omega\end{array}$ & $\begin{array}{l}\longrightarrow \longleftarrow 25 \mathrm{мг/л} \\
-500 \mathrm{мг/л}\end{array}$ \\
\hline
\end{tabular}

C

Рис. 1. Динамика прорастания семян Alisma plantago-aquatica $(A)$, Sium latifolium $(B)$, Juncus effusus $(C)$ /

Fig. 1. Dynamics of Alisma plantago-aquatica (A), Sium latifolium $(B)$ and Juncus effusus $(C)$ seeds germination (on the abscissa axis - Time (days), on the ordinate axis - Germination (\%). Control; 1-10-25-50-100-250-500 mg/1 
Та же закономерность наблюдалась и в контроле, т.е. это не являлось следствием действия сульфата цинка. Действие $\mathrm{Zn}^{2+}$ проявлялось в колебаниях этого показателя при разных концентрациях. Более низкие концентрации стимулировали прорастание семян у всех видов. При остальных концентрациях лабораторная всхожесть оставалась высокой у частухи, т.е. ее семена оказались более устойчивыми к действию сульфата цинка. О том, что низкие концентрации $\mathrm{Zn}^{2+}$ не влияли на всхожесть семян, а высокие уменьшали ее незначительно, сказано в [9].

Семена поручейника резко замедлили процесс прорастания при 250 мг/л и выше. У ситника лабораторная всхожесть резко падала, начиная с концентрации 50 мг/л, и становилась близкой нулю при 100 . При 250 и 500 мг/л семена этого вида не прорастали.

Данные по динамике прорастания семян показали, что основная их часть прорастала к 5-м суткам у частухи, к 9-м - у поручейника и к 6-7-м - у ситника (рис. 1). При этом быстрее, чем в контроле, семена прорастали на растворах сульфата цинка у частухи почти при всех концентрациях, у ситника - при 1 и 25 мг/л, у поручейника - как в контроле, т.е. при концентрации $1-25 \mathrm{мг/л.}$

Таким образом, выявлен предел токсичности для прорастания семян ситника развесистого, находящийся между 100 и 250 мг/л. Уменьшение токсичности $\mathrm{Zn}^{2+}$ при высоких концентрациях (повышение лабораторной всхожести у поручейника при 100 мг/л и у частухи при 250 мг/л) могло быть связано с активацией защитных механизмов от действия ТМ за счет образования комплексов с низкомолекулярными соединениями в клетке. Разная реакция семян на действие $\mathrm{Zn}^{2+}$, возможно, объясняется различиями в их строении и размерах: у ситника развесистого семена размером 0,2-1 мм, у частухи подорожниковой - 3-5 мм, клетки семенной кожуры крупные, с утолщенными стенками, у поручейника широколистного - 2 мм, на их поверхности имеются ребра. Плотная оболочка экзокарпия семян последних двух видов оказалась непроницаема для сульфата цинка почти при всех концентрациях. Эффект воздействия ТМ на процесс прорастания, как и у наземных растений, зависит от способности проникать через покровы семян. Способность семян развиваться в токсичной среде обусловлена тем, что оболочка пропускает кислород и воду, а ТМ задерживает. Они начинают действовать после разрушения оболочки.

В работе Е.М. Ивановой и соавт. [10] отмечалось, что цинк на начальных этапах онтогенеза менее токсичен, чем медь. Ингибирование прорастания семян рапса цинком начиналось при концентрации, в 30 раз превышавшей начальную концентрацию меди, а 50\%-ное ингибирование и летальный эффект он вызывал при концентрации в 20 раз большей, чем медь. В наших экспериментах также показано, что сульфат цинка менее токсичен, чем сульфаты никеля и меди. Так, для поручейника при действии сульфата никеля наблюдалось значительное снижение лабораторной всхожести при 250 и 500 мг/л, 
у частухи - при 500 мг/л сульфата никеля и 50 мг/л сульфата меди [11]. Установлены пределы токсичности прорастания семян поручейника (сульфата меди - между 100 и 250 мг/л) и ситника (сульфат никеля - между 10 и 25 мг/л, сульфат меди - между 25 и 50 мг/л). Все это подтверждает более сильный токсический эффект солей никеля и меди по сравнению с солью цинка.

Влияние сульфата цинка на развитие проростков. У всех трех видов нормальное развитие проростков наблюдали при 1-25 мг/л. Они имели семядольные листья и хорошо развитые корни (см. таблицу). При этом в варианте с концентрацией 10 мг/л у проростков поручейника окраска листьев была интенсивнее, чем в контроле. В литературе также отмечалось, что низкие концентрации $\mathrm{Zn}^{2+}$ повышают количество зеленых пигментов и активизируют кущение побегов [6, 9]. При концентрациях 25-100 мг/л у проростков поручейника и частухи выявили уменьшение интенсивности окраски и размеров семядольных листьев. У ситника изменения интенсивности окраски листьев ни при одной из концентраций не зафиксировали.

При концентрациях 50-100 мг/л у всех видов зафиксировали отмирание корней проростков и некроз листьев. На снижение массы корней при действии концентрации $\mathrm{Zn}^{2+} 21$ мг/л у урути колосистой и его угнетающее действие на развитие корней у шелковника волосистолистного, но при меньших концентрациях $(0,01-0,1$ мг/л), указывалось в $[12,13]$. Рост корней подавлялся за счет угнетения растяжения клеток [14]. Интенсивность фотосинтеза снижалась за счет уменьшения площади листа, содержание хлорофилла при этом не изменялось [6]. На симптом токсичности $\mathrm{Zn}^{2+}$, проявляющийся в некрозах листьев, указывалось и в [15].

У частухи при концентрациях 250 и 500 мг/л проростки начали погибать на 5-е сутки, при 50-100 мг/л - на 8-е. У поручейника проростки отмирали при 100 мг/л на 13-е сутки, при 250 и 500 мг/л - почти сразу после проклевывания корешком зародыша покровов семени. Проростки ситника развесистого при 50 мг/л отмирали на 10-е сутки, при 100 мг/л - сразу после их проклевывания.

В целом же проростки ситника оказались менее устойчивы к действию сульфата цинка - уже при 100 мг/л - у них не отмечалось позеленения семядолей и появления семядольных листьев. Возможно, ингибирование формирования проростков сульфатом цинка видоспецифично.

Для проростков соль цинка также оказалась менее токсична, чем соли никеля и меди. У частухи и поручейника при 100 мг/л сульфата никеля и 50 мг/л сульфата меди не развивались семядольные листья. Начиная с 50 мг/л солей никеля и меди у поручейника и 10 мг/л у ситника, было отмечено отмирание проростков. Однако основные признаки проявления токсичности оказались сходны - угнетение роста главного корня и некроз листьев [16].

\section{Заключение}

Более устойчивы к действию сульфата цинка семена частухи подорожниковой: лабораторная всхожесть оставалась высокой при всех концентрациях. Се- 
мена поручейника широколистного резко замедлили процесс прорастания при концентрации ионов цинка 250 мг/л. У семян ситника развесистого выявлен предел токсичности сульфата цинка для прорастания (между 100 и 250 мг/л).

У всех трех видов исследуемых растений наблюдалось нормальное развитие проростков при концентрации ионов цинка в среде 1-25 мг/л. При концентрациях 50-100 мг/л у всех видов выявлено отмирание корней проростков и некроз листьев. Менее устойчивыми к действию сульфата цинка оказались проростки ситника развесистого. Выявлено увеличение устойчивости видов к действию сульфата цинка в зависимости от обводненности их местообитаний: наиболее устойчив гелофит, средняя устойчивость отмечена у гелогигрофита, наименьшая - у гигрофита.

\section{Лumepamypa}

1. Добровольский В.В. Тяжелые металлы: загрязнение окружающей среды и глобальное рассеяние // Тяжелые металлы в окружающей среде. М. : Изд-во МГУ, 1980. С. 3-12.

2. Мур Дж., Рамамурти С. Тяжелые металлы в природных водах. Контроль и оценка влияния. М. : Мир, 1987. С. 177-203.

3. Косицын Н.В., Алексеева-Попова Н.В. Действие тяжелых металлов на растения и механизмы металлоустойчивости (обзор) // Растения в экстремальных условиях минерального питания. Л. : Наука, 1983. С. 5-22.

4. Устойчивость к тяжелым металлам дикорастущих видов / под ред. Н.В. АлексеевойПоповой. Л. : Наука, 1991. С. 214.

5. Ильин В.Б., Гармаш Г.А., Гармаш Н.Ю. Влияние тяжелых металлов на рост, развитие и урожайность сельскохозяйственных культур // Агрохимия. 1985. № 6. С. 90-100.

6. Khudsar T., Mahmooduzzafar N., Jqbal M., Sairam R.K. Zinc-induced changes in morphophysiological and biochemical parameters in Artemisia annua // Biol. Plant. 2004. Vol. 48. P. 255-260.

7. Wang C., Zhang S.H., Wang P.F., Hou J., Zhang W.J., Li W., Lin Z.P. The Effect of Excess $\mathrm{Zn}$ on Mineral Nutrition and Antioxidative response in rapeseed Seedling // Chemosphere. 2009.Vol. 75. P. 1468-1476.

8. Вредные химические вещества. Неорганические соединения I-IV групп : справ. изд. / под ред. В.А. Филова и др. Л. : Химия,1988. С. 18-34.

9. Казнина Н.М., Титов А.Ф., Лайдинен Г.Ф., Таланов А.В. Устойчивость щетинника зеленого к повышенным концентрациям цинка // Известия РАН. Сер. Биология. 2009. № 6. С. $677-684$.

10. Иванова Е.М., Холодова В.П. Кузнеиов Вл.В. Биологические эффекты высоких концентраций солей меди и цинка и характер их взаимодействия в растениях рапса // Физиология растений. 2010. Т. 57, № 6. С. 864-873.

11. Крылова Е.Г. Влияние сульфата никеля на прорастание семян и развитие проростков прибрежно-водных растений // Журнал Сибирского федерального университета. Биология. 2010. Т. 3, № 1. С. 99-106.

12. Лапиров А.Г., Лебедева О.А. Влияние азотнокислых солей некоторых тяжелых металлов на начальные этапы онтогенеза шелковника волосистолистного (Batrachium tricjophyllum) (Chaix) Bosch.) // Вестник Томского государственного университета. 2009. № 323. C. 364-369.

13. Stoyanova D.P., Tchakolova E.S. Cadmium-induced ultrastructural changes in chloroplasts of the leaves and stems parenchyma in Myriophyllum spicatum // Physiol. Plant. 1997. Vol. 34. P. 241-248. 
14. Ruano A., Poschenrieder Ch., Boacelo J. Growth and biomass partitioning in zinc-toxic bush beans // J. Plant Nutr. 1988. Vol. 11, № 5. P. 577-588.

15. Singh M.V. Response of rice (Oryza sativa) and wheat (Triticum aestivum) to phosphorus and zinc fertilization on sodic soils // Indian J. Agr. Sci. 1988. Vol. 58, № 11. P. 823-826.

16. Крылова Е.Г. Токсичность солей никеля и меди для семян и проростков рдеста гребенчатого (Potamogeton pectinatus L.), частухи подорожниковой (Alisma plantagoaquatica L.), поручейника широколистного (Sium latifolium L.) и ситника скученного (Juncus conglomerates L.) // Токсикологический вестник. 2010. № 1. С. 41-44.

Поступила в редакиию 06.09.2013 г.; повторно 21.11.2013 г.; принята 15.02.2014 2.

Крылова Елена Геннадьевна - канд. биол. наук, с.н.с. лаборатории высшей водной растительности Института биологии внутренних вод им. И.Д. Папанина РАН (п. Борок, Ярославская обл., Россия). E-mail: panova@ibiw.yaroslavl.ru

Tomsk State University Journal of Biology. 2014. № 2 (26). P. 151-160

doi: $10.17223 / 19988591 / 26 / 10$

\section{Elena G. Krylova}

Laboratory of Higher Aquatic Plants, I.D. Papanin Institute for Biology of Inland Waters, Russian Academy of Sciences, Borok, Russian Federation.

E-mail: panova@ibiw.yaroslavl.ru

\section{Coastal and water plants seed germination and seedling development under the influence of zinc sulphate}

The effect of zinc sulfate $(1-500 \mathrm{mg} / \mathrm{l})$ on Alisma plantago-aquatica L., Sium latifolium L. and Juncus effusus L. seed germination and seedling development was studied. We collected seeds from plants in August and September 2008 in Yaroslavl oblast, on humid banks of small rivers, the Ild' and the Latka. Then, after a cold wet stratification for 4-5 months, we germinated 25 pieces in lyuminostate in petri dishes at the temperature of $20-25^{\circ} \mathrm{C}$ on filter paper soaked with solutions of salts $\mathrm{ZnSO}_{4} \times 7 \mathrm{H}_{2} \mathrm{O}$ at different concentrations. There were three replicates, illumination 3200 lux, photoperiod 9/15 (light/dark). The experiment lasted for 15 days. Control - distilled water. We determined laboratory germination and carried out monitoring of seedling development. We found out that low concentrations (1-10 mg / 1) stimulated germination in all species. At concentrations of $25-500 \mathrm{mg} / 1$, Alisma plantago-aquatica L. laboratory germination rate remained high, i.e. the seeds of this species proved to be resistant to the action of the studied TM. Sium latifolium L. seeds were marked by germination process slowing at $250 \mathrm{mg} / 1$ and more. Juncus effusus L. laboratory germination decreased sharply, starting with $50 \mathrm{mg} / \mathrm{l}$. At 250 and $500 \mathrm{mg} / \mathrm{l}$ the seeds of this species did not germinate. It should be noted that Alisma plantago-aquatica L. seeds germinated faster than in control for almost all concentrations of zinc sulfate, Juncus effusus L. - at 1 and $25 \mathrm{mg} / \mathrm{l}$ and Sium latifolium L. as in control - at 1-25 mg/l.

All three species showed normal development of seedlings at $1-25 \mathrm{mg} / \mathrm{l}$. They had cotyledon leaves and well-developed roots. With the option of $10 \mathrm{mg} / \mathrm{l}$, Sium latifolium L. seedlings leaf color was more intense than in the control, and at 25$100 \mathrm{mg} / \mathrm{l}$ these seedlings and those of Alisma plantago-aquatica L. were marked by a decrease in intensity of the color and the size of cotyledons. We did not fix 
any changes of Juncus effusus L. leaf color intensity at any concentration which did not hinder their development. Concentrations at 50 and $100 \mathrm{mg} / \mathrm{l}$ caused leaves and roots necrosis of seedlings of all species. At concentrations of 250 and $500 \mathrm{mg} / \mathrm{l}$, Sium latifolium L. seedlings died (shortly after the embryo root pipping the seed cover). However, at 50-100 mg/l, Alisma plantago-aquatica L. and Juncus effusus L. seedlings died earlier. In general, Juncus effusus L. seedlings were less resistant to zinc sulfate - already at $100 \mathrm{mg} / \mathrm{l}$ and they did not show cotyledon greening and they did not have cotyledon leaves.

The article contains 1 table, 1 figure, 16 ref.

Key words: zinc sulfate; seed germination; seedling development; Alisma plantago-aquatica; Sium latifolium; Juncus effusus.

\section{References}

1. Dobrovol'skij VV. Tyazhelye metally: zagryaznenie okruzhayushchey sredy i global'noe rasseyanie [Heavy metals: environmental pollution and global scattering]. Tyazhelye metally v okruzhayushchey srede [In: Heavy metals in the environment]. Moscow: Moscow State University Press; 1980. p. 3-12. In Russian

2. Mur Dzh., Ramamurti S. Tyazhelye metally v prirodnykh vodakh. Kontrol' i otsenka vliyaniya [Heavy metals in natural waters. Monitoring and evaluation of the impact]. Moscow: Mir; 1987. p. 177-203. In Russian

3. Kosicin AV, Alekseeva-Popova NV. Deystvie tyazhelykh metallov na rasteniya i mekhanizmy metalloustoychivosti (obzor) [The effect of heavy metals on plants and mechanisms of metal resistance (review)]. Rasteniya v ekstremal'nykh usloviyakh mineral'nogo pitaniya [In: Plants in the extreme conditions of mineral nutrition. Ecological and physiological studies]. Leningrad: Nauka; 1983. p. 5-22. In Russian

4. Ustoychivost' $\mathrm{k}$ tyazhelym metallam dikorastushchikh vidov [Resistance of wild species to heavy metals]. Alekseeva-Popova NV, editor. Leningrad: Nauka; 1991. 214 p. In Russian

5. Il'in VB, Garmash GA, Garmash NJu. Vliyanie tyazhelykh metallov na rost, razvitie i urozhaynost' sel'skokhozyaystvennykh kul'tur [Influence of heavy metals on the growth, development and productivity of crops]. Agrokhimiya. 1985;6:90-100. In Russian

6. Khudsar T, Mahmooduzzafar N, Jqbal M, Sairam R.K. Zinc-induced changes in morphophysiological and biochemical parameters in Artemisia annua. Biol. Plant. 2004;48:255260.

7. Wang C, Zhang SH, Wang PF, Hou J, Zhang WJ, Li W, Lin ZP. The Effect of Excess Zn on Mineral Nutrition and Antioxidative response in rapeseed Seedling. Chemosphere. 2009;75:1468-1476.

8. Vrednye khimicheskie veshchestva. Neorganicheskie soedineniya I-IV grupp: Sprav. izd. [Harmful chemicals. Inorganic compounds of I-IV groups]. Filova VA i dr, editor. Lenngrad: Khimiya; 1988. p.18-34. In Russian

9. Kaznina NM, Titov AF, Lajdinen GF, Talanov AV. Green foxtail resistance to elevated zinc concentrations. Izvestiya. Biology Series. 2009;6:677-684. In Russian

10. Ivanova EM, Holodova VP, Kuznecov VIV. Biological effects of high concentrations of copper and zinc salts and the nature of their interaction in rape plants. Russian Journal of Plant Physiology. 2010;57(6):806-814.

11. Krylova EG. Effect of nickel sulfate on seed germination and seedling development of coastal aquatic plants. Journal of Siberian Federal University. Biology. 2010;3(1):99-106. In Russian 
12. Lapirov AG, Lebedeva OA. Influence of nitrate salts of some heavy metals on the initial stages of Batrachium trichophyllum ontogeny (Chaix) Bosch. Vestnik of Tomsk State University. 2009;323:364-369. In Russian

13. Stoyanova DP, Tchakolova ES. Cadmium-induced ultrastructural changes in chloroplasts of the leaves and stems parenchyma in Myriophyllum spicatum. Physiol. Plant. 1997:34:241248.

14. Ruano A, Poschenrieder Ch, Boacelo J. Growth and biomass partitioning in zinc-toxic bush beans. J. Plant Nutr. 1988;11(5):577-588.

15. Singh MV. Response of rice (Oryza sativa) and wheat (Triticum aestivum) to phosphorus and zinc fertilization on sodic soils. Indian J. Agr. Sci.1988;58(11):823-826.

16. Krylova EG. Toxicity of nickel and copper for seeds and seedlings of Potamogeton pectinatus L., Alisma plantago-aquatica L., Sium latifolium L. and Juncus conglomerates L. Toxicological review. 2010;1:41-44. In Russian

Received 6 September 2013;

Revised 21 November 2013; Accepted 15 February 2014 2. 